\title{
Physiological state of female and light intensity affect the host-plant selection of carrot psyllid, Trioza apicalis (Hemiptera: Triozidae)
}

\author{
ANNE NISSINEN $^{1,2}$, LINA KRISTOFFERSEN ${ }^{3}$ and OLLE ANDERBRANT ${ }^{3}$ \\ ${ }^{1}$ MTT Agrifood Research Finland, Plant Protection, FI-31600 Jokioinen, Finland; e-mail: anne.nissinen@mtt.fi \\ ${ }^{2}$ Department of Environmental Science, University of Kuopio, P.O. Box 1627, FI-70211 Kuopio, Finland \\ ${ }^{3}$ Pheromone Group, Chemical Ecology and Ecotoxicology, Department of Ecology, Lund University, Sölveg. 37, SE-223 62 Lund, \\ Sweden
}

Key words. Triozidae, Trioza apicalis, host-plant selection, Daucus carota, Picea abies, light intensity, light gradient, host preference, behaviour, physiological state

\begin{abstract}
We have studied the effect of different light gradient regimes on host-plant selection of the carrot psyllid, Trioza apicalis Förster. In both a strong and a weak light gradient, carrot psyllids preferred a carrot leaf placed in higher light intensity. When the choice was between the host (carrot Daucus carota L.) and a non-host (barley Hordeum vulgare L.) virgin adults settled significantly more often on non-host in higher light intensity than on carrot in lower light intensity. In a weak light gradient, none of the gravid females settled on a non-host. In an experiment without light gradient, gravid females showed a preference for carrot, whereas virgin females settled approximately equally on Norway spruce Picea abies Karst. (winter shelter plant) and carrot. Our results show that virgin and gravid individuals have different host-plant selection behaviour, and that they are sensitive to small differences in light intensity. Both factors can create a source of variation in behavioural assays, and should be taken into consideration in future experiments with this and probably also related species. Our results suggest that carrot psyllids can utilize visual cues (light intensity or wavelength) in host-plant selection, and the role of visual cues should be more thoroughly studied.
\end{abstract}

\section{INTRODUCTION}

The carrot psyllid (Trioza apicalis Förster) is one of the major pests on carrots (Daucus carota L.) in northern Europe. Carrot psyllids over-winter as adults on conifers of which Norway spruce (Picea abies Karst.) is the preferred species (Láska, 1974; Kristoffersen \& Anderbrant, 2005, 2007). Over-wintered adults migrate to carrot fields in late May or early June (Láska, 1974; Rygg, 1977; Tiilikkala et al., 1996; Burckhardt \& Freuler, 2000) and damage the crop by feeding on the carrot leaves. The growth of the damaged carrots is stunted: the leaves are curled and the roots become small and deformed (Markkula et al., 1976; Rygg, 1977). Over-wintered adults remain alive on carrot up to eight weeks (Rygg, 1977). Eggs were detected on the carrots ten days after the first trap catches (Rygg, 1977), which may suggest that the carrot psyllid mates on carrot, the average preoviposition period being 9.7 days (Rygg, 1977). The average oviposition to adult development time is 52-62.9 days (Láska, 1974; Rygg, 1977) and the new generation usually starts to emerge in mid August. The adults of the new generation migrate $0-5$ days after their emergence (Láska, 1974). According to Burckhardt \& Freuler (2000) the autumn migration continues until November. However, Láska (1974) did not observe any autumn migration at temperatures below $11^{\circ} \mathrm{C}$.

The carrot psyllid is a specialist herbivore and it is reasonable to believe that olfaction plays a major part in host recognition. Studies have shown the presence of several olfactory sensilla on the antennae (Kristoffersen et al.,
2006), which are responsive to various host-plant odours (Kristoffersen et al., in prep.). Some field experiments with repellents have been performed (Nehlin et al., 1994), but behavioural assays with carrot psyllids have been difficult to conduct under laboratory conditions. Over the last few years, we have unsuccessfully tried several behavioural bioassay designs in attempts to explore the activity of various olfactory and/or visual stimuli. Assay designs have included a range of arena types and sizes, choice and no-choice tests, walking and flying bioassays, with or without airflow (unpubl. data). We have obtained inconclusive or contradictory results using different methods (e.g., choice tests between carrot and spruce in cages or olfactometer). Similar problems in finding a suitable behavioural assay have been described for the citrus psyllid, T. erytreae (Del Guercio) (Moran, 1968). Schoonhoven (1968) suggested that the reason for the unwillingness of insects to respond to chemical extracts was due to lack of contact sensory input from the plant substrate. However, we have tried using whole plant material, plant extracts, headspace collections, and single synthetic compounds with little or no success (unpubl. data).

As results varied from experiment to experiment, we suspected that the behavioural responses of virgin and gravid individuals might differ or that there is some uncontrolled variation in the laboratory conditions. In preliminary experiments, carrot psyllids moved readily towards light (unpubl. data), so we designed experiments to study the effect of light conditions more carefully. Phototaxis has been observed and studied in Hemiptera in 
relation to flight (Dixon \& Mercer, 1983; Blackmer \& Byrne, 1993; Blackmer et al., 1995), mate finding (Hunt \& Nault, 1991), aggregation behaviour (Michaud, 1999) and settling behaviour (White, 1970).

The aim of the study was to investigate the effect of light conditions on the behaviour of carrot psyllids in different physiological stages. We wanted to determine whether the attraction to light is stronger than the attraction to a host plant, and whether choices are the same in virgin males and females and in gravid females. The null hypothesis was that attraction to light is not stronger than to host plant, since we expected a carrot specialist to prefer carrot (Valterová et al., 1997) regardless of the environmental conditions. We predicted that gravid females would choose the preferred oviposition host (i.e. carrot) over other options more often than the virgin individuals, since it is the newly emerged individuals that migrate to over-wintering sites (i.e. conifers) in the autumn (Láska, 1974). We also predicted that virgin insects would display stronger positive phototaxis than gravid individuals, since Rygg (1977) found that the correlation between trap catches and sunlight hours was stronger in autumn than in summer.

\section{MATERIAL AND METHODS}

\section{Insects}

Carrot psyllids were obtained from a culture, originating from insects collected in the field in Sweden and Finland, and reared on carrot for several generations at the Department of Ecology, Lund University. Psyllids were reared in 20L : 4D period, 20 : $15^{\circ} \mathrm{C}$ (day : night) temperature program and in $40 \%$ r.h. Gravid females, showing egg-laden swollen abdomens, were collected from the colony. Some nymphs were maintained separately on carrot seedlings in 1-litre jars with net lids. When adults began to emerge, they were collected twice a day from the containers. Virgin adults were held separately in Eppendorf tubes that contained a detached carrot cotyledon until experiments were initiated (3 to 8 days). Wilting cotyledons were replaced with new ones.

\section{Plants}

Plant material was grown in a climate chamber under the same conditions as the insects. Barley (Hordeum vulgare) was selected as a non-host plant. Both carrots (Daucus carota ssp. sativus cv. Nestor) and barley were sown at approximately 30 seeds per pot in 1.45-litre pots filled with commercial soil mixture (Balkong \& Växthusjord, Hasselfors Garden, Sweden). Carrot seedlings were from 3.5 to 7.5 weeks old and barley seedlings $1-2.5$ weeks old when used in experiments. Branches of the winter shelter tree, Norway spruce, were cut from trees near Lund and brought to the lab, and fresh twigs were used for each round of experiments.

\section{Behavioural assays}

A series of choice experiments (Table 1) were performed in horizontally positioned transparent Plexiglass cylinders $(\varnothing 14.5$ $\mathrm{cm}$, length $30.5 \mathrm{~cm}$ ) (Fig. 1a). Both ends were sealed with thin, white cotton cloth (b). A detached carrot or barley leaf or a spruce twig was inserted through Parafilm into a 4-ml vial (c) filled with tap water. The vial was fixed on the floor with double-sided sticky tape at either end of the cylinder cage at 4 $\mathrm{cm}$ from the edge. In each cylinder, the two pieces of plant material used as stimuli were of approximately equal weight and
TABle 1. An overview of the two-choice experiments conducted in this study.

\begin{tabular}{ccc}
\hline Experiment & $\begin{array}{c}\Delta \text { Light } \\
\left(\mu \mathrm{mol} / \mathrm{m}^{2} / \mathrm{s}\right)^{\mathrm{a}}\end{array}$ & $\begin{array}{c}\text { Stimuli; position } \\
(\text { light intensity })\end{array}$ \\
\hline
\end{tabular}

Strong light gradient tests

$\begin{array}{lll}1 & 6.2 & \text { carrot; high }- \text { carrot; low } \\ 2 & 6.2 & \text { carrot; low - barley; high }\end{array}$

Weak light gradient tests

$\begin{array}{llc}3 & 1.5 & \text { carrot }- \text { barley; random } \\ 4 & 1.5 & \text { carrot; high - carrot; low }\end{array}$

No light gradient tests

$5 \quad 0-0.1 \quad$ carrot - spruce; random

${ }^{a} \Delta$ Light is the difference in light intensity between the two ends of a test cage. Each experiment ran for $24 \mathrm{~h}$, and during the first $8 \mathrm{~h}$ the positions of the insects were recorded every two hours. Number of replicates was 24 in all the experiments except in experiment 2 for virgin males, where $n=21$.

size. Carrot leaves or barley shoots used in an experiment at the same time were from different plant individuals. The spruce twigs were from the same tree, but we used new shoot tips in each experiment. A single carrot psyllid was released in each cylinder from an Eppendorf tube (d) which was fixed with dental wax (e) at the centre of the cylinder. The position of a psyllid, i.e. either on the cylinder walls or on the plant, was observed 2, 4, 6, 8 and $24 \mathrm{~h}$ after the beginning of the experiment. Experiments started between 9 and 12 a.m. and were ended after $24 \mathrm{~h}$, when the final reading was made. The light regime was the same as in the culture, 20L : 4D, dark between 00.00 and 04.00 . The behaviour of virgin females, virgin males (both 3-8 days old) and gravid females (2 to 8 weeks old) was tested in the experiments with 24 replicates, except the carrotbarley test in strong light gradient for males with only 21 replicates. There were 8 cages under the light fitting during one day at similar conditions and each arrangement was replicated during three consecutive days for all three groups of insects. Each individual was used in the experiment only once. Unless otherwise indicated the results illustrated in figures represent the choice of the psyllids after $24 \mathrm{~h}$. Binomial and $\chi^{2}$-tests were performed using SPSS 14.0 for Windows.

\section{Strong, weak and no light gradient tests}

Two-choice tests with a strong light gradient were conducted at room temperature in a 20L:4D regime on a table under diffuse light (approximately 5000 lux or $9 \mu \mathrm{mol} / \mathrm{m}^{2} / \mathrm{s}$ ). A light fitting equipped with six similar 36W Philips Master PL-L 830/4P

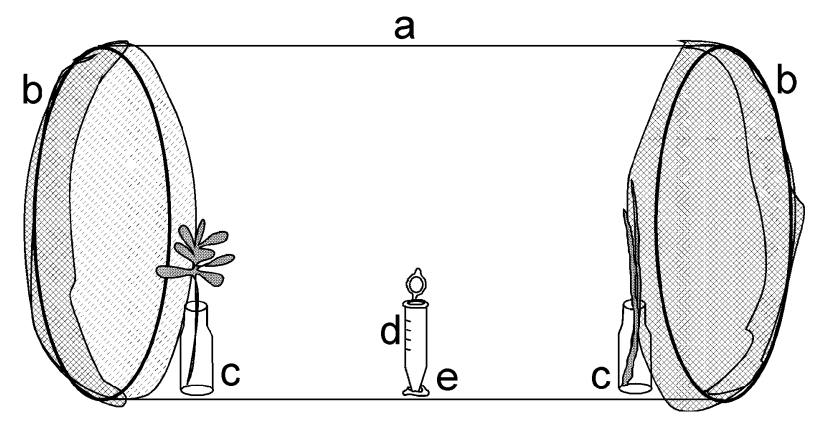

Fig. 1. Schematic drawing of the choice setup. a - plexiglass cylinder, $\mathrm{b}$ - thin, white cotton cloth, c - 4-ml vial, d - Eppendorf tube where the insect was released, e - a piece of dental wax. 


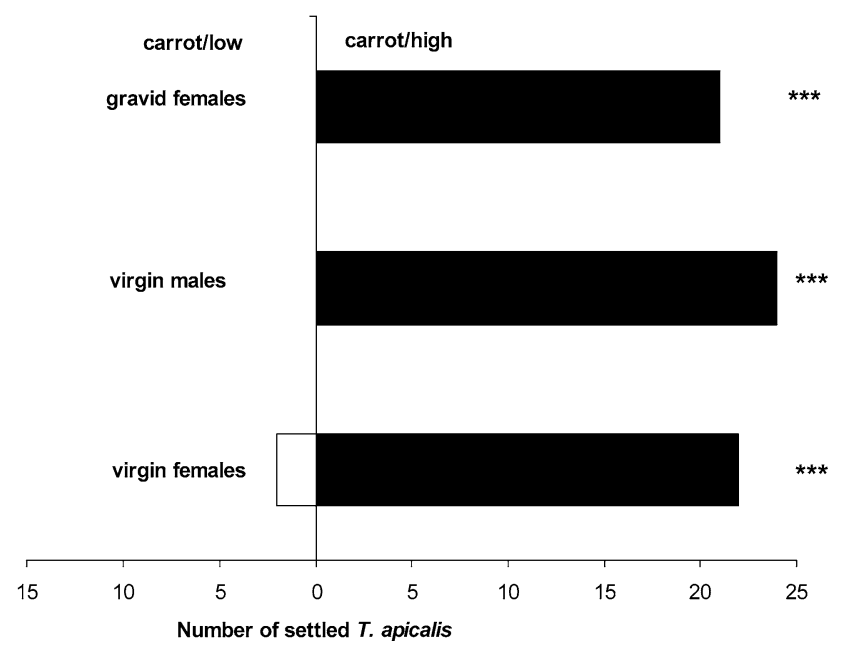

Fig. 2. Number of settled carrot psyllids $(n=24)$ in the strong light gradient two-choice experiment (experiment 1), where one carrot leaf was placed in higher and another in lower light intensity. The average difference in light intensity between the ends of a cage was $6.2 \mu \mathrm{mol} / \mathrm{m}^{2} / \mathrm{s}$. All three categories of insects settled in the high light end (binomial tests, $\mathrm{p}<0.001$ ).

bulbs (emitting warm white light with intensity peaks around 550 and $610 \mathrm{~nm}$ ) in row and covered by white Plexiglass was used. There were no other light sources in the room. Light intensity was measured using a PAR Quantum light sensor SKP200 (Skye Instruments Ltd., UK).

In experiment 1 , one bulb was removed in both ends of the light fitting i.e. four bulbs were used and test cylinders were placed under the edges (both ends) of the light fitting so that the direction of the cylinder was in 90 degrees angle to the direction of the bulbs. The cylinders were arranged to produce a difference in light intensity of approximately $6.2 \mu \mathrm{mol} / \mathrm{m}^{2} / \mathrm{s}$ between the two ends of every test cylinder (strong light gradient). The choice was between two carrot leaves of equal weight and age. The only measured difference between the ends of the cylinders was the light intensity. In experiment 2 , the plant placed in the higher light intensity end was a non-host, a barley shoot tip. At the other end of the cylinder, in lower light intensity, we placed a carrot leaf of equal weight.

In experiments 3 and 4 , five bulbs of the light fitting were used and test cylinders were placed on the table in the same direction as the bulbs. One end of the cylinders faced a white wall, reflecting the light and causing a weak light gradient: on average $1.5 \mu \mathrm{mol} / \mathrm{m}^{2} / \mathrm{s}$ between the ends of a cylinder. In experiment 3 , the choice was between carrot and barley. The setup was the same as in experiment 2 with the exception that barley shoots and carrot leaves were randomly placed at the ends of a cylinder (i.e. in higher or lower light intensity). In experiment 4 , the choice was between carrot leaves of equal weight and age.

In experiment 5 , we evened out the light gradient so that the difference in light intensity was $0-0.1 \mu \mathrm{mol} / \mathrm{m}^{2} / \mathrm{s}$. Arrangement of cylinders in relation to light bulbs was the same as in experiments 3 and 4 . White cloth screens were used around the cylinders to create the required even light conditions in these experiments. A carrot leaf and a tip of a spruce shoot of equal weight were randomly placed in either end of the cylinder.

\section{RESULTS}

\section{Strong light gradient tests}

In experiment 1 , carrot psyllids clearly preferred a carrot leaf placed in higher light intensity (binomial tests,

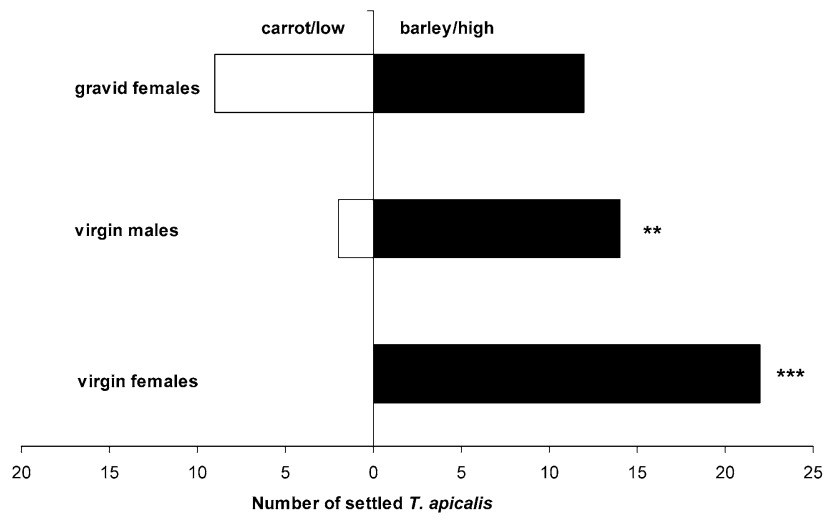

Fig. 3. Number of settled carrot psyllids $(n=24$, except virgin males $n=21$ ) in a two-choice experiment (experiment 2), where a carrot leaf was placed in lower and a tip of barley shoot in higher light intensity. The average difference in light intensity between the ends of a cage was $6.2 \mu \mathrm{mol} / \mathrm{m}^{2} / \mathrm{s}$. Virgin insects preferred to settle in the high light end (binomial tests, $\mathrm{p}$ $<0.001$ for virgin females, $\mathrm{p}<0.01$ for virgin males, ns for gravid females).

$\mathrm{p}<0.001$ for all three groups) to an equal carrot leaf placed in the low light end (Fig. 2). Experiment 2 featured a non-host barley shoot placed in the high light intensity end of the cylinder. Here, all virgin females settled on barley, virgin males significantly preferred barley, while there was no significant difference in the number of gravid females settled on carrot or on barley (binomial tests; virgin females $p<0.001$, virgin males $p<0.01$, gravid females $\mathrm{p}=0.664 \mathrm{~ns}$ ) (Fig. 3). None of the virgin females were ever observed on carrot, all went directly to the higher light end. Out of four virgin males first observed on barley, two left it and two changed to carrot. One gravid female was observed changing hosts from barley to carrot under the strong light gradient.

\section{Weak light gradient tests}

When given the choice between randomly placed carrot and barley in a weaker light gradient $\left(1.5 \mu \mathrm{mol} / \mathrm{m}^{2} / \mathrm{s}\right)$ in experiment 3, all three groups displayed positive phototaxis. However, there was a significant difference in host-

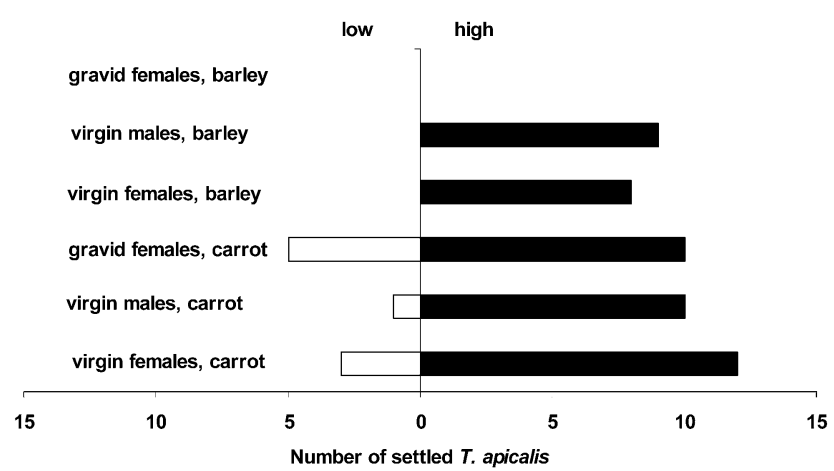

Fig. 4. Number of settled carrot psyllids $(n=24)$ in experiment 3 , where carrot leaves and barley shoot tips were randomly placed in a low or high light intensity. The average difference in light intensity between the ends of a cage was 1.5 $\mu \mathrm{mol} / \mathrm{m}^{2} / \mathrm{s}$. 


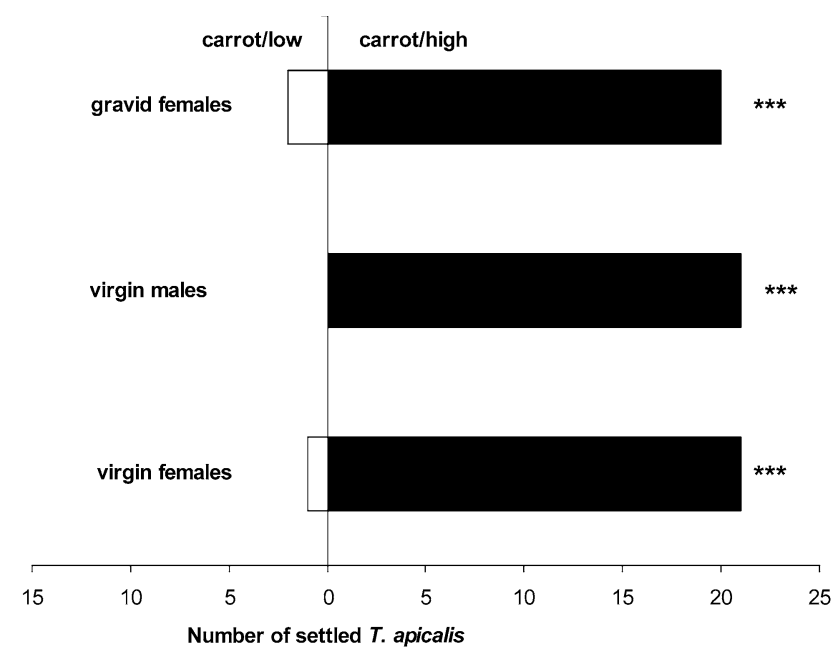

Fig. 5. Number of settled carrot psyllids $(n=24)$ in the weak light gradient two-choice experiment (experiment 4), where one carrot leaf was placed in higher and another in lower light intensity. The average difference in light intensity between the ends of a cage was $1.5 \mu \mathrm{mol} / \mathrm{m}^{2} / \mathrm{s}$. The number of settled carrot psyllids was tested with binomial tests, showing a strong preference for the higher light intensity in all groups $(\mathrm{p}<0.001)$.

plant selection between the different insect groups $\left(\chi^{2}\right.$-test, $\left.\mathrm{p}=0.023\right)$. None of the gravid females settled on barley after $24 \mathrm{~h}$, while $35 \%$ of the virgin females and $45 \%$ of the virgin males settled on the non-host, i.e. in the higher light intensity end (Fig. 4). No psyllid settled on a barley leaf placed in lower light intensity. Again, none of the virgin females changed their initial choice, whereas one of the virgin males moved from barley to carrot. Two virgin males and three gravid females were first observed on barley, but after $24 \mathrm{~h}$ they had left barley. In experiment 4 , we repeated the two-choice test with two equal carrot leaves at this lower light intensity difference, and carrot psyllids still settled on a carrot leaf placed in the higher light intensity end of the cylinder (binomial tests, $p$ $<0.001$ for all three groups) (Fig. 5).

\section{No light gradient tests}

In experiment 5, we came close to eliminating the difference in light intensity at the ends of the test cylinders and gave psyllids the choice between carrot and spruce. Gravid, egg-laden females preferred settling on carrot (binomial test, $\mathrm{p}<0.05$ ) (Fig. 6). Virgin males and virgin females behaved differently: the females settled randomly on either the winter or summer host, whereas males to a large extent settled on carrot (binomial test, $\mathrm{p}=0.82$, ns and $\mathrm{p}<0.01$, respectively). Two virgin females switched hosts from spruce to carrot, and one male first settled on spruce, but left and did not settle again.

\section{DISCUSSION}

Our results clearly demonstrate the importance of light on the behaviour of carrot psyllids, and that different categories of adults behave differently. Virgin females and males significantly preferred barley leaves placed in the higher light intensity end of the test cylinders, while gravid females did not show any preference. In the weak

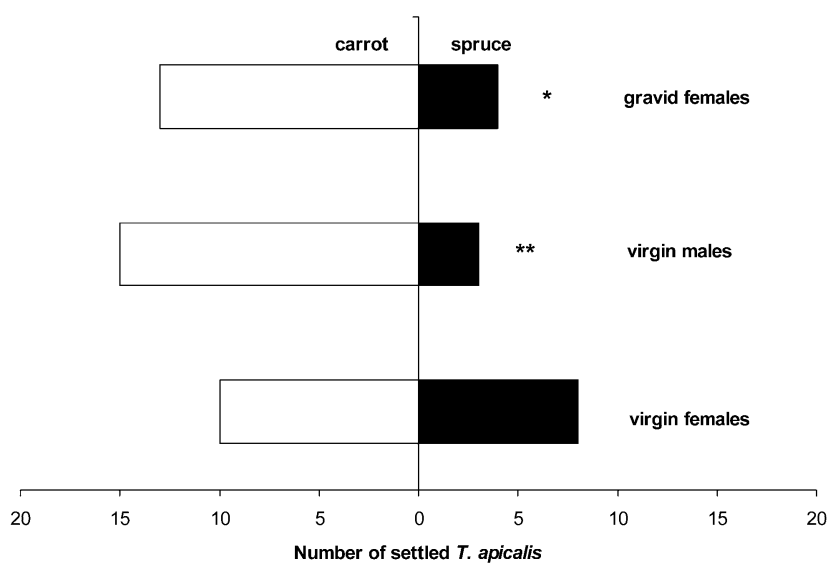

Fig. 6. Settled carrot psyllids $(n=24)$ after $24 \mathrm{~h}$ in a twochoice experiment between carrot and spruce. Light intensity conditions were virtually even, $0-0.1 \mu \mathrm{mol} / \mathrm{m}^{2} / \mathrm{s}$ between the ends of a cage (experiment 5). Gravid females preferred settling on carrot, as did the virgin males (binomial tests, $p<0.05$ and $p$ $<0.01$, respectively). Virgin females showed no preference.

light gradient, none of the gravid females were settled on barley after $24 \mathrm{~h}$, while $35-45 \%$ of virgin adults were. Under even light conditions, gravid females significantly preferred carrot over spruce, while virgin females did not show any preference. Clearly, the host selection behaviour differs between these two groups. Virgin adults could be more prone to accept a non-host, since they make up the autumn migration cohort (Láska, 1974). Carrot psyllids die within $24 \mathrm{~h}$ without a plant to settle on, but they are able to survive on herbaceous non-hosts for 4-6 days, which may facilitate migration (Rygg, 1977). The difference in host-plant selection behaviour of virgin and gravid female psyllids could be due to egg development, which can change the nutritional requirements of a female (Schoonhoven et al., 2005).

In all experiments, the carrot psyllids had direct access to live host plant material and therefore could utilize visual, olfactory and gustatory cues. When the choice was between carrot and carrot the psyllids settled consistently on the carrot leaf in higher light intensity. Shape and colour of the leaf are unlikely to affect the choice, as we used similar-aged leaves from the same cultivar. There are some differences in the volatile emissions of individual carrots (Nissinen et al., 2005), but due to the random placement of seedlings used in the experiments, it is highly unlikely that this could explain our results. Still, the possibility remains that the higher light intensity affected the level of photosynthesis and thus increased the volatile emission. Previously the volatile emissions of carrot have been collected at approximately 100-150 $\mu \mathrm{mol} / \mathrm{m}^{2} / \mathrm{s}$ and $250 \mu \mathrm{mol} / \mathrm{m}^{2} / \mathrm{s}$ (Nissinen et al., 2005), and there were considerably lower emission levels in the lower light intensity. However, it is quite unlikely that the $1.5-6.2 \mu \mathrm{mol} / \mathrm{m}^{2} / \mathrm{s}$ differences in light intensity in the present experiment would significantly affect the emission rates.

When psyllids were given the choice between carrot and barley in the strong light gradient the virgin adults 
significantly more often selected barley than carrot. To our knowledge, barley has not been reported as a hostplant of carrot psyllid (Burckhardt, 1986; Ossiannilsson, 1992) and carrot psyllids survived only from a few days to two weeks on other Poaceae species (Rygg, 1977; Valterová et al., 1997). Therefore, the clear preference of virgin adults for barley in this case where the main host, carrot, was available is surprising. However, adult psyllids have been observed to feed on a wide range of other plants than those where nymphs can develop (Hodkinson, 1974). Volatile cues of barley should not attract a carrot specialist more than volatile cues of carrot, regardless of possible differences in emission rates. Also, the shape of carrot leaf is quite typical and if the selection is based on the shape of the leaf we would expect it to favour carrot over barley. However, we cannot exclude the possibility that the colour of the leaf has affected the host-plant selection. Previously, it has been shown that Ctenarytaina eucalypti (Maskell) and C. spatulata (Taylor) can perceive the colour of the juvenile and adult leaves of Eucalyptus globulus (Brennan \& Weinbaum, 2001). Similarly, Heteropsylla cubana Grawford can utilize both colour and intensity of reflected light in host plant selection (Lapis \& Borden, 1995). However, if the colour of barley leaf was in fact more attractive than the colour of carrot leaf, we would have expected the psyllids to prefer barley also in a weak light gradient. In contrast, gravid females preferred carrot and virgin adults did not show a clear preference. Therefore, we consider the difference in light intensity as the most probable reason for the observed host-plant selection in experiments $1-4$.

The carrot psyllids showed strong positive phototactic behaviour. It has earlier been shown that the close relative Trioza erytreae, like many other insects, is positively phototactic (Moran, 1968; Van Den Berg et al., 1990). For T. erytreae this behaviour is said to serve the purpose of leading the insects up toward the youngest shoots of their host plants, where availability of nutrients is most suitable (Van Den Berg et al., 1990).

The strong attraction towards higher light intensity among virgin carrot psyllids may be attributed to migratory behaviour. Previously, Harada (1991) has shown that the strength of positive phototaxis in adult Gerris lacustris latiabdominis (Miyamoto) (Heteroptera: Gerridae) changes seasonally as a function of photoperiod. Migrating adults exhibit strong phototaxis from April to midsummer and thereafter the phototaxis gradually decreases. In nature, the new generation of carrot psyllid will migrate to conifers. The highest number of take-offs occurs 1-5 days after the emergence of new adults in August-October (Láska, 1974). Our findings of a strong phototaxis among virgin adults are in agreement with Rygg (1977), who found that the correlation between trap catches and sunlight hours was stronger in September, when air temperatures are lower, than in summer. In most migratory species the migration occurs before reproduction (Gatehouse, 1997). The carrot psyllids are also unlikely to mate before migration. Valterová et al. (1997) showed that the critical photoperiod for oviposition is
17L : 7D. In southern Finland or central Sweden the day length has shortened to about $16 \mathrm{~h}$ by mid August, when the new generation usually starts to emerge.

In experiment 5, gravid females and virgin males showed a preference for carrot, whereas virgin females settled approximately equally on Norway spruce and carrot. The light intensity difference was minimized, thus the choice of the psyllids must have been based on plantderived cues. Previously, Valterová et al. (1997) showed that the olfactory cues from both conifers and carrot are surprisingly similar. Subsequently, Kristoffersen et al. (in prep.) showed that both female and male carrot psyllids have the same types of olfactory sensilla on the antenna and most of the sensilla are able to respond both to conifer and carrot volatiles. However, Kristoffersen et al. (in prep.) found a trend of a particular male sensillum responding more strongly to carrot extract than the corresponding sensillum of females, which could be one reason for the different behaviour of virgin males and females. However, females are usually more responsive to plant volatiles than males (Blackmer \& Cañas, 2005). This has previously been shown e.g. in Cacopsylla bidens (Šlc) where males were less sensitive to host-plant volatiles than females, even though no sexual dimorphism was found in the antennae (Soroker et al., 2004).

In our previous Y-tube olfactometer experiments the carrot psyllids did not prefer carrot or spruce, whereas in cage experiments they did show a preference. This may suggest that carrot psyllids also need visual cues (shape or colour) for host-plant recognition. Synergism of visual and olfactory cues has been shown in the orientation behaviour of a leafhopper (Todd et al., 1990) and Lygus hesperus (Knight) (Blackmer \& Cañas, 2005). Another possible explanation for previous failures in Y-tube olfactometer experiments could be too low concentrations of volatile cues. Recently, Kristoffersen et al. (in prep.) showed that the maximum sensillar responses were obtained at quite high concentrations $(1-100 \mu \mathrm{g})$ of the active compounds, which may suggest that the olfactory system of carrot psyllid is adjusted to plants occurring in large stands such as spruce. This is actually supported by Kristoffersen \& Anderbrant (2007) who found more psyllids in larger conifer stands compared to smaller groups of trees. Therefore, one or a few leaves of carrot may not emit volatiles in concentrations high enough to produce a sensillar response.

Our results show that virgin and gravid carrot psyllid individuals exhibit different host-plant selection and settling behaviour. Further we also proved that carrot psyllids are able to sense and respond to very low differences in light intensity (300 lux or $1.5 \mu \mathrm{mol} / \mathrm{m}^{2} / \mathrm{s}$ ) and are strongly positively phototactic. These results should be seriously considered when planning behavioural assays under laboratory conditions. The difficulties of creating light conditions even enough for this species complicates, or can totally hinder, successful behavioural studies and attempts to evaluate the effect of olfactory stimuli in the laboratory. In addition, we cannot exclude the possibility that rearing a host-alternating species constantly in 
summer conditions could affect their behaviour and therefore we recommend conducting behavioural assays in the field. Furthermore, the role of visual cues in host-plant selection of carrot psyllid needs to be more thoroughly studied.

ACKNOWLEDGEMENTS. This study was supported by an award from the Fund of University of Kuopio and from the August Johannes ja Aino Tiuran maatalouden tutkimussäätiö, as well as by The Swedish Research Council for Environment, Agricultural Sciences and Spatial Planning (Formas).

\section{REFERENCES}

BlackMER J.L. \& Byrne D.N. 1993: Environmental and physiological factors influencing phototactic flight of Bemisia tabaci. Physiol. Entomol. 18: 336-342.

BlaCKMER J.L. \& CAÑAS L.A. 2005: Visual cues enhance the response of Lygus hesperus (Heteroptera: Miridae) to volatiles from host plants. Environ. Entomol. 34: 1524-1533.

Blackmer J.L., BYrne D.N. \& Tu Z. 1995: Behavioral, morphological, and physiological traits associated with migratory Bemisia tabaci (Homoptera: Aleyrodidae). J. Insect Behav. 8: 251-267.

Brennan E.B. \& Weinbaum S.A. 2001: Psyllid responses to colored sticky traps and the colors of juvenile and adult leaves of the heteroblastic host plant Eucaluptus globulus. Environ. Entomol. 30: 365-370.

BurCKHARDT D. 1986: Taxonomy and host plant relationships of the Trioza apcalis Förster complex (Hemiptera, Homoptera: Triozidae). Entomol. Scand. 16: 415-432.

Burckhardt D. \& Freuler J. 2000: Jumping plant-lice (Hemiptera: Psylloidea) from sticky traps in carrot fields in Valais, Switzerland. Mitt. Schweiz. Entomol. Ges. 73: 191-209.

Dixon A.F.G. \& Mercer D.R. 1983: Flight behaviour in the sycamore aphid: factors affecting take-off. Entomol. Exp. Appl. 33: 43-49.

Gatehouse A.G. 1997: Behavior and ecological genetics of wind-borne migration by insects. Annu. Rev. Entomol. 42: 475-502.

HaRADA T. 1991: Effects of photoperiod on phototaxis in Gerris lacustris latiabdominis (Heteroptera: Gerridae). Environ. Entomol. 20: 1149-1154.

Hodkinson I.D. 1974: The biology of the Psylloidea (Homoptera): a review. Bull. Entomol. Res. 64: 325-339.

Hunt R.E. \& NaUlT L.R. 1991: Roles of interplant movement, acoustic communication, and phototaxis in mate-location behaviour of the leafhopper Graminella nigrifrons. Behav. Ecol. Sociobiol. 28: 315-320.

Kristoffersen L. \& Anderbrant O. 2005: Host plant ecology of the carrot psyllid (Trioza apicalis). IOBC/WPRS Bull. 28(4): 129-132.

Kristoffersen L. \& Anderbrant O. 2007: Carrot psyllid (Trioza apicalis) winter habitats - insights in shelter plant preference and migratory capacity. J. Appl. Entomol. 131: 174-178.

Kristoffersen L., Hallberg E., Wallén R. \& Anderbrant O. 2006: Sparse sensillar array on Trioza apicalis (Homoptera, Triozidae) antennae - an adaptation to high stimulus levels? Arthropod Struct. Dev. 35: 85-92.
LAPIS E.B. \& BORDEN J.H. 1995: Role of wavelength-specific reflectance intensity in host selection by Heteropsylla cubana Crawford (Homoptera: Psyllidae). Pan-Pac. Entomol. 71: 209-216.

LÁsKA P. 1974: Studie über den Möhrenblattfloh (Trioza apicalis Först.) (Triozidae, Homoptera). Acta Sci. Nat. Acad. Sci. (Brno) 8: 1-44.

Markkula M., Laurema S. \& TittTanen K. 1976: Systemic damage caused by Trioza apicalis on carrot. Symp. Biol. Hung. 16: 153-155.

MiCHAUD J.P. 1999: Aggregation by alatae of Toxoptera citricida (Homoptera: Aphididae). Environ. Entomol. 28: 205-211.

Moran V.C. 1968: Preliminary observations on the choice of host plants by adults of the citrus psylla, Trioza erytreae (Del Guercio) (Homoptera: Psyllidae). J. Entomol. Soc. Sth. Afr. 31: 403-410.

Nehlin G., Valterová I. \& Borg-Karlson A.K. 1994: Use of conifer volatiles to reduce injury caused by carrot psyllid, Trioza apicalis, Förster (Homoptera, Psylloidea). J. Chem. Ecol. 20: 771-783.

Nissinen A., Ibrahim M., Kainulainen P., Tillikkala K. \& Holopainen J. 2005: Influence of carrot psyllid (Trioza apicalis) feeding or exogenous limonene or methyl jasmonate treatment on composition of carrot (Daucus carota) leaf essential oil and headspace volatiles. J. Agric. Food Chem. 53: $8631-8638$.

Ossiannilsson F. 1992: The Psylloidea (Homoptera) of Fennoscandia and Denmark. Fauna Entomologica Scandinavica 26. E.J. Brill, Leiden, 348 pp.

RYGG T. 1977: Biological investigations on the carrot psyllid Trioza apicalis Förster (Homoptera, Triozidae). Meld. Nor. Landbrukshogsk. 56: 1-20.

Schoonhoven L.M. 1968: Chemosensory bases of host plant selection. Annu. Rev. Entomol. 13: 115-136.

Schoonhoven L.M., van LoOn J.J.A. \& Dicke M. 2005: InsectPlant Biology. 2nd ed. Oxford University Press, Oxford, 421 pp.

Soroker V., Talebaev S., Harari A.R. \& Wesley S.D. 2004: The role of chemical cues in host and mate location in the pear psylla Cacopsylla bidens (Homoptera: Psyllidae). J. Insect Behav. 17: 613-626.

Tillikkala K., Ketola J. \& Taivalmaa S.L. 1996: Monitoring and threshold values for control of the carrot psyllid. IOBC/WPRS Bull. 19(11): 18-24.

Todd J.L., Phelan P.L. \& Nault L.R. 1990: Interaction between visual and olfactory stimuli during host-finding by leafhopper, Dalbulus maidis (Homoptera: Cicadellidae). J. Chem. Ecol. 16: 2121-2133.

Van den Berg M.A., Deacon V.E. \& De Jaeger K. 1990: Ecology of the citrus psylla, Trioza erytreae (Hemiptera: Triozidae). 1. Daily activities and habits of adults. Phytophylactica 22: 323-328.

Valterová I., Nehlin G. \& Borg-Karlson A.K. 1997: Host plant chemistry and preferences in egg-laying Trioza apicalis (Homoptera, Psylloidea). Biochem. Syst. Ecol. 25: 477-491.

White T.C.R. 1970: The nymphal stage of Cardiaspina densitexta (Homoptera: Psyllidae) on leaves of Eucalyptus fasciculosa. Aust. J. Zool. 18: 273-293.

Received November 7, 2007; revised and accepted February 8, 2008 